Отримано: 4 квітня 2018 р.

Прорецензовано: 29 травня 2018 р.

Прийнято до друку: 1 червня 2018 р.

e-mail: kitevs@i.ua

DOI: $10.25264 / 2519-2558-2018-2(70)-23-27$
Ibragimova S. Reproduction des particularites syntaxiques des notices de medicament françaises dans la traduction ukrainienne. Наукові записки Національного університету «Острозька академія»: серія «Філологія». Острог : Вид-во НаУОА, 2018. Вип. 2(70), червень. С. 23-27.

Svitlana Ibragimova,

professeur de français du département de la théorie, de la pratique et de la traduction du français,

Université nationale technique de l'Ukraine "Institut polytechnique de Kiev Igor Sikorski»

\title{
REPRODUCTION DES PARTICULARITES SYNTAXIQUES DES NOTICES DE MEDICAMENT FRANÇAISES DANS LA TRADUCTION UKRAINIENNE
}

L'étude de la spécificité des textes du discours technique et scientifique y compris des textes pharmaceutiques est la base de la portée primordiale dans la formation universitaire de futurs professionnels dans le domaine de la traduction de spécialité.

$L$ 'article proposé examine les particularités syntaxiques des textes du discours pharmaceutiques auxquels appartiennent les instructions pharmaceutiques et les notices d'utilisation d'un médicament. On fait l'étude des caractéristiques et particularités de la syntaxe des textes descriptifs, informatifs, explicatifs et injonctifs étant objet de la pragmatique. L'objet de l'analyse est considéré par l'ensemble des catégories syntaxiques, des formes et des constructions correspondantes de deux langues à comparer qui provoquent de nombreux problèmes de traduction.

A la base de l'analyse comparative des textes pharmaceutiques dans la langue française et celle de la langue de traduction (ukrainienne) on étudie en détail les combinaisons de mots appelés syntagmes et les phrases qui sont usuelles et caractéristiques pour les notices françaises de médicament, on constate les lois générales et particulières de leur fonctionnement.

Les résultats de la recherche révèlent l'impact des particularités syntaxiques sur l'effet pragmatique des notices de médicament et sert de base pour l'analyse des moyens de la reproduction des particularités syntaxiques des textes français du discours pharmaceutique dans la traduction ukrainienne.

Mots-clés : discours pharmaceutique, textes spécialisés, notices françaises d'utilisation d'un médicament, particularités syntaxiques, transformations de traduction, spécificité de la syntaxe, effet pragmatique.

Ібрагімова Світлана Володимирівна,

старший викладач кафедри теорії, практики та перекладу франиузької мови,

Національний технічний університет Украӥни « Київський політехнічний інститут імені Ігоря Сікорського»,

\section{ОСОБЛИВОСТІ ПЕРЕКЛАДУ СИНТАКСИЧНИХ КОНСТРУКЦІЙ ФРАНЦУЗЬКИХ ІНСТРУКЦЙ ДО МЕДИЧНИХ ПРЕПАРАТІВ}

У пропонованій статті розглядаються синтаксичні особливості франиузьких текстів спеціалізованого фармацевтичного дискурсу, до яких відносяться фармачевтичні інструкиї та вкладиші до вживання лікарських препаратів. Представлено аналіз характерних рис та особливостей синтаксису описових та інформативних фармацевтичних франиузьких текстів. На підставі порівняльного аналізу фармацевтичних текстів мов оригіналу та перекладу докладно описуються результати дослідження, висвітлюється вплив синтаксичних особливостей на досягнення прагматичного ефекту при перекладі текстів франиузьких інструкиій до вживання лікарських препаратів украӥнською мовою.

Ключові слова: фармацевтичний дискурс; спечіалізовані тексти; франиузькі інструкиї̈ до вживання лікарських препаратів; перекладацькі трансформачії, синтаксичні особливості; прагматичний ефект.

Ибрагимова Светлана Владимировна,

старший преподаватель кафедры теории, практики и перевода франиузского языка,

Национальный технический университет Украины «Киевский политехничный институт имени Игоря Сикорского»

\section{ОСОБЕННОСТИ ПЕРЕВОДА СИНТАКСИЧЕСКИХ КОНСТРУКЦИЙ ФРАНЦУЗСКИХ ИНСТРУКЦИЙ МЕДИЦИНСКИХ ПРЕПАРАТОВ}

В предлагаемой статье рассматриваются синтаксические особенности франиузских текстов специализированного фармаиевтического дискурса, к которым относятся медицинские инструкиии и вкладыши к медицинским препаратам. Представлен анализ характерных черт и особенностей синтаксиса описательных и информационных типов франиузских фармацевтических текстов. На основе сравнительного анализа текстов оригинала и перевода детально описываются результать исследования, раскрывается влияние синтаксических особенностей на достижение прагматического эффекта при переводе текстов франиузских инструкций и вкладышей кмедицинским препаратам на украинский язык.

Ключевые слова: фармацевтический дискурс, специализированный текст, французские инструкции, вкладыши кмедицинским препаратам, переводческие трансформации, синтаксические особенности, прагматический эффект.

Présentation du problème scientifique et de son importance. Le discours des textes techniques et scientifiques fait partie du cursus universitaire de futurs professionnels dans le domaine de la traduction spécialisée. La spécificité des textes pharmaceutiques appartenant à ce type de discours peut créer des difficultés supplémentaires et représenter des problèmes considérables pour les étudiants philologues, les débutants et les non-spécialistes. Nous avons déjà analysés ses particularités linguistiques et extralinguistiques dans nos recherches antérieures. Cette étude est consacrée aux phénomènes typiques et particularités syntaxiques de ce genre de textes qui ne correspondent pas toujours à ceux du système de la langue ukrainienne. 
Divers scientifiques et spécialistes prêtent leur attention à l'analyse des caractéristiques et particularités des textes pharmaceutiques : G.P. Bourova, L.M. Nossova ont étudié les aspects différents du discours pharmaceutique, la composition et la structure des instructions et notices françaises d'utilisation d'un médicament, N.Y. Antonova, A.V. Botsman ont fait des recherches sur leur précision communicative et pragmatique, K.S. Makéev a délimité les genres des textes pharmaceutiques et médicaux fréquemment traduits en ukrainien. Mais pour les traducteurs du français en ukrainien de ce type de texte il y a beaucoup de questions liées aux approches de la traduction professionnelle des textes à aborder. Dans les programmes universitaires la formation des étudiants philologues orientée vers la traduction professionnelle de ce type de textes exige la nécessité de la recherche et l'élaboration ultérieure. Cela justifie l'intérêt et l'actualité de notre étude.

L'objectif du travail vise à établir les non-coïncidences entre les particularités syntaxiques des notices françaises d'utilisation d'un médicament et celles ukrainiennes en faisant la recherche sur la spécificité et les divergences entre les systèmes pertinents de deux langues et les méthodes et moyens de traduction appropriés pour franchir les difficultés de traduction.

L'objet de l'analyse est considéré par l'ensemble des catégories syntaxiques et morphologiques, des formes et des constructions correspondantes de deux langues qui provoquent de nombreux problèmes de traduction.

Différents approches de la définition du concept étudié. En faisant l'étude des travaux théoriques de divers scientifiques et spécialistes étudiant le discours technique et scientifique y compris les textes du discours pharmaceutique il faut constater qu'il existe la diversité de classifications des transformations de traduction de différents auteurs.

L.K. Latychev base sa classification sur la nature des correspondances entre deux langues à analyser et sur le caractère de leurs non-coïncidences pertinentes. Selon lui, les transformations de traduction touchent différents niveaux de la langue: lexical, morphologique, syntaxique, grammatical, et même le niveau de la production et de la planification du discours [4, p. 252-258]. Par conséquent, les transformations liées aux niveaux de la langue sont considérées comme les plus caractéristiques et appelées «mixtes» car au cours de la traduction du texte premier on assiste à la combinaison de différentes méthodes de niveau, de contenu et celles «spécifiques» $[4$, p.261].

La classification des transformations de traduction de V. N. Komissarov distingue les transformations:

- lexicales: translittération, transcription, calquage, remplacements lexico-sémantiques regroupant concrétisation, généralisation et modulations;

- grammaticales: assimilation syntaxique (traduction mot à mot), intégration de deux propositions dans une proposition (assemblage), division d'une proposition par deux (dislocation), remplacements grammaticaux (de parties du discours, des formes grammaticales, regroupement des membres de la proposition);

- complexes: transformations lexico - grammaticales incluant la traduction antonymique, traduction explicative et compensation [3, p.170-198].

Dans la classification d'Y. I. Retsker tous les types de transformation de traduction font partie des catégories suivantes:

- modification de l'ordre des mots;

- regroupement des membres de la proposition, de parties du discours;

- reconstruction de la structure syntaxique (partielle et totale);

- ajouts et omissions de mots [6, p.22].

En résumant les transformations de traduction, il est à noter que les classifications de V. N. Komissarov et d'Y. I. Retsker sont à la base de notre recherche.

Les particularités syntaxiques de la traduction des notices de médicament et des instructions pharmaceutiques françaises se reproduisent tout d'abord car il y a des changements et modifications au niveau de la phrase. Dans l'exemple tiré de la notice Lamisil $1 \%$ crème on constate que l'équivalence de l'image soumise à la logique de la présentation de l'information dans la notice française (LE) et celle de traduction(LT) n'est pas totale: l'information dans la française et la pertinence de l'information rapportée dans la ukrainienne est modifiée à cause du volume de l'information présentée : le texte français de la rubrique Adultes et enfants de plus de 12 ans comporte 10 propositions dont 4 premières sont numérotées(contenu important) et 6 autres concrétisent et expliquent l'information complémentaire soumise dans le point 4. Le texte de la traduction ukrainienne Дорослим та дітям від 12 років сотрогte seulement 4 propositions qui couvrent le même volume de l'information présentée en français. Donc, on assiste au phénomène de la pertinence sélective due à l'équivalence pragmatique quand le message aux destinataires se distingue par :

- le volume des connaissances sur la situation : la notice française a une structure différente à celle du texte traduit en ukrainien car elle unit deux paragraphes Adultes et enfants de plus de 12 ans et Fréquence et durée d'application de Lamsil crème dans la même rubrique Comment utiliser Lamisil 1\% crème? Contrairement, le texte de la traduction en ukrainien contient une seule rubrique intitulée Спосіб застосування та дози qui englobe l'information que l'auteur de l'original a trouvée nécessaire d'informer ;

- et le but pragmatique(en LE la notice est orientée plus directement aux consommateurs car elle précise que c'est l'information pour l'utilisateur; en ukrainien l'information est destinée non seulement aux utilisateurs non spécialistes mais aux spécialistes dans les domaines pharmaceutiques et médicaux.

Comme conséquence, on voit les modifications et changements :

- de l'ordre des propositions : les phrases soulignées apparaissent exclusivement dans un des deux textes à comparer ;

- de la structure syntaxique caractérisée par:

1. le remplacement de la construction impérative par celle déclarative:

Nettoyez et séchez soigneusement la zone infectée.

Перед нанесенням крему необхідно ретельно очистити $i$ підсушити уражені ділянки.

3. l'assemblage de deux propositions à une seule proposition :

2. Appliquez ensuite Lamisil crème en fine couche sur cette zone et celle qui l'entoure.

3. Frictionnez légèrement.

Крем наносять тонким шаром на уражену шкіру і прилеглі ділянки, злегка втираючи.

5. l'omission des propositions supplémentaires françaises dans le texte de la notice ukrainienne: Nettoyez-vous les mains après 
avoir touché la zone infectée, afin de ne pas transmettre l'infection à une autre zone ou à quelqu'un d'autre. Les maladies fongiques sont très contagieuses : ne partagez pas vos vêtements et votre linge de maison avec quelqu'un d'autre. Lavez-les fréquemment. Essayez de ne pas gratter les zones atteintes, même si elles chatouillent. Ceci pourrait aggraver la situation, retarder le processus de guérison et propager l'infection.

6. l'introduction des propositions supplémentaires dans la structure du texte de traduction : la proposition ukrainienne KpeM Ламізил наносять на шкіру 1 або 2 рази на добу залежно від захворювання n'existe pas dans la notice française, elle est ajoutée dans le texte de traduction;

7. la modification de la structure syntaxique : la phrase française comporte deux propositions :

- dont la première est la proposition complexe à la subordonnée de condition Si vous traitez une zone située dans un pli et la proposition principale vous pouvez la couvrir d'une bande de gaze qui est développée par le complément circonstanciel de temps mis en apposition tout particulièrement la nuit

- et la seconde est la proposition impérative Remplacez la gaze à chaque utilisation.

Lors de la traduction on recourt aux transformations suivantes : la phrase française comportant deux propositions a été modifiée en une proposition complexe contenant la principale місия нанесення можна вкривати марлею accompagnée de deux compléments circonstanciels de temps dont l'un est à la fin de la phrase mis en apposition : особливо на ніч: et l'autre est au début При інфекиіях асcompagné de la subordonnée relative : щъо супроводжуються зопрілістю qui est à son tour développée par l'énumération des zones affectées exprimées par les compléments circonstanciels de lieu homogènes mis entre parenthèses: (nід молочними залозами, у між пальцевій зоні, паховій ділянці і між сідницями).

Si vous traitez une zone située dans un pli, vous pouvez la couvrir d'une bande de gaze, tout particulièrement la nuit. Remplacez la gaze à chaque utilisation.

Observons l'exemple 2 tiré de la notice OTIPAX:

Contre-indications du médicament

OTIPAX

Ce médicament ne doit pas être utilisé dans les cas suivants :

- allergie aux anesthésiques locaux,

- perforation du tympan.

Attention

Bien que ce médicament puisse être vendu sans ordonnance, faites vérifier l'absence de perforation de votre tympan par un médecin.
При інфекиіях, щзо супроводжуються зопрілістю (під молочними залозами, у між пальцевій зоні, паховій ділянці $i$ між сіднииями), місия нанесення можна вкривати марлею, особливо на ніч.

\section{Протипоказання}

Гіперчутливість до діючих речовин, будь-яких компонентів препарату або до амідних місцевоанестезуючих лікарських засобів. Перфорація барабанної перетинки травматичного або інфекційного походження (див. розділ «Особливості застосування»). Особливості застосування

Перед будь-яким застосуванням препарату слід перевірити цілісність барабанної перетинки (як запобіжний захід). Якщо є деструкція барабанної перетинки, введення препарату у вухо може призвести до контакту препарату зі структурами середнього вуха, викликаючи побічні реакції у цих тканинах.

L'analyse de la rubrique Contre-indications du médicament OTIPAX démontre que le texte français contient une proposition simple avec deux contre-indications : allergie aux anesthésiques locaux et perforation du tympan. Mais la variante de traduction en ukrainien est organisée comme deux syntagmes nominaux bien développés ou on concrétise :

- les cas de l'allergie : Гіперчутливість до діючих речовин, будь-яких компонентів препарату або до амідних місиевоанестезуючих лікарських засобів ;

- les cas de perforation du tympan : Перфораиія барабанної перетинки травматичного або інфекиійного походження (див. розділ «Особливості застосування»).

Ce type d'ajout e mots supplémentaires dans la structure de la phrase dans la LT est typique pour les notices ukrainiennes car cela s'explique par des raisons pragmatiques : orientation vers le milieu plus large des destinataires ukrainiens (non-spécialistes et professionnels) ce qui entraine les transformations syntaxiques au niveau de la phrase telles que :

- les variations diverses de l'image de la phrase : le remplacement de la proposition simple sur deux syntagmes nominaux bien développés à plusieurs termes homogènes;

- les ajouts de l'information supplémentaire (див. розділ «Особливості застосування») changent l'ordre des propositions et causent la différenciation des structures syntaxiques du texte premier(TP) et du texte traduit(TT) : le texte français applique une précaution sur la contre-indication : Bien que ce médicament puisse être vendu sans ordonnance, faites vérifier l'absence de perforation de votre tympan par un médecin. La proposition complexe française (à la subordonnée de concession et à la proposition principale impérative) est modifiée dans la traduction en deux propositions ukrainiennes. La première est simple : Перед будь-яким застосуванням препарату слід перевірити иілісність барабанної перетинки (як запобіжний захід). La proposition principale impérative française faites vérifier l'absence de perforation de votre tympan par un médecin est remplacée sur la proposition incitative avec la construction слід перевірити иілісність барабанної перетинки асcompagnée du regroupement des membres de la proposition dû à la modification de l'ordre des termes de la phrase: l'inversion du complément circonstanciel (CC) de temps placé au début de la proposition: Перед будь-яким застосуванням препарату. Cette inversion du CC est inévitable puisque la seconde proposition ukrainienne comporte l'explication détaillée des conséquences possibles indésirables qui est absente dans le texte français mais nécessaire dans la traduction pour des raisons du transfert de la structure thème-rhème de la phrase ukrainienne: Якщ̧o $\epsilon$ деструкиія барабанної перетинки, введення препарату у вухо може призвести до контакту препарату зі структурами середнього вуха, викликаючи побічні реакції у цих тканинах.

Il est important pour les notices de médicament françaises le recours aux propositions impératives où l'impératif français est traduit par son correspondant ukrainien au niveau pragmatique équivalent :

N'appliquez pas d'autres médicaments sur les zones traitées.

Не використовуйте інші ліки на оброблені ділянки.

Au niveau syntaxique il n'y a pas de transformations. 
Mais en revanche, on a trouvé des cas où le contenu pragmatique de l'impératif français est interprété et traduit avec moins de correspondances. Ce sont des cas de traduction de l'impératif français par le syntagme ukrainien слід/не слід +infinitif du verbe :

Lamisil crème est uniquement destiné à une utilisation cutanée (sur la peau). Ne l'utilisez pas dans la bouche ou ne l'avalez pas.

Dans la version de la traduction ukrainienne l'effet pragmatique de l'impératif est plus atténué et adouci car les syntagmes français ne l'utilisez pas et ne l'avalez pas expriment l'exigence et l'interdiction très nettes. Dans le contexte de la version de la traduction ukrainienne on observe la répartition du sens de l'interdiction catégorique sur le titre de la rubrique Особливі застереження et sur le syntagme тільки для зовнішнього застосовування pour compenser la perte du sens catégorique et éviter de l'imprécision dans la transmission de ce sens. Au niveau des transformations syntaxiques c'est le cas du remplacement de la construction impérative sur celle déclarative.

A partir des exemples cités, on peut conclure que dans la traduction les propositions impératives françaises ne sont pas toujours reproduites à l'aide de la construction pertinente ukrainienne ce qui entraîne la non-coïncidence ou la coïncidence partielle du potentiel pragmatique du texte source.

Les propositions simples sont typiques pour la syntaxe française des textes du discours pharmaceutique car elles servent à nommer la situation donnée à l'étape concrète de la parole afin de transmettre l'information sans explications supplémentaires :

1. Ce médicament est disponible sans prescription médicale.

2. Vous devez toujours utiliser ce médicament en suivant scrupuleusement les informations fournies dans cette notice ou par votre médecin ou votre pharmacien.

\section{1. Цей препарат доступний без рецепта лікаря.}

2. Ви завжди повинні використовувати цей препарат у точній відповідності з інформачією, що міститься в даному документі.

Dans la traduction ce type de propositions simples subit des transformations syntaxiques :

- au niveau du syntagme (ex.1) : le syntagme prépositionnel français sans prescription médicale (Prep.+ N.+Adj.) a son correspondant ukrainien без рецепта лікаря (Prep. $+N .+N$.), le changement syntaxique est le résultat de la transformation lexicale de concrétisation ;

- au niveau de la proposition (ex.2) : le syntagme les informations fournies dans cette notice ou par votre médecin ou votre pharmacien est traduit en ukrainien par la proposition subordonnée relative інформацією, що міститься в даному документі. On observe le changement de la structure syntaxique de la proposition française simple par la proposition complexe à la subordonnée relative ukrainienne et l'omission d'un syntagme français ou par votre médecin ou votre pharmacien. On pourrait expliquer ces transformations par le but pragmatique d'éviter les détails excessifs pour simplifier la perception de l'information par le destinataire.

Mais les textes des notices françaises de médicament abondent en propositions complexes qui sont exploitées pour expliquer, préciser, exprimer les détails.

1. Les parties de la proposition coordonnée sont liées entre elles par

- les termes de coordination appelées aussi « conjonctions de coordination »: mais, ou, et, donc, or, ni, car:

Elle a l'apparence d'une rougeur circulaire, peut être squameuse (écailleuse) et elle peut chatouiller.

\section{Вона має вигляд кругової висипки, може лущчитися і свер- бimu.}

- ou bien par un adverbe de liaison appelée aussi « connecteur », pouvant indiquer la cause, la conséquence, l'opposition, etc. : et puis, par conséquent

2. Les phrases qui ont une proposition principale commandant les autres propositions et d'autres secondaires, dépendantes, $\underline{\text { su- }}$ bordonnées. On distingue des subordonnées relatives, complétives, interrogatives, circonstancielles. Les propositions subordonnées se caractérisent par les moyens spécifiques de subordination qui organisent la structure hiérarchique de la phrase entre la principale et la subordonnée. Ce sont:

- les conjonctions que, si, comme ;

- les pronoms qui, que, lequel, dont;

- mots de liaison ou, quand, combien.

3. Le troisième type de la phrase complexe française est la proposition juxtaposée. Elles sont très fréquentes à l'oral ou elles sont séparées par une pause, un petit temps d'arrêt. Mais à l'écrit, elles sont séparées par des virgules. Dans les textes des notices de médicament françaises la proposition juxtaposée est de faible fréquence.

Il (ibuprofène) est contre-indiqué chez l'enfant en cas de varicelle et chez la femme enceinte au-delà de six mois, le paracétamol étant plus indiqué dans ces deux cas.
Він протипоказаний дітям з вітрянкою і жінкам з вагітністю більше шести місяців, паращетамол є більш відповідним в обох випадках.

Dans la proposition juxtaposée citée il s'agit simplement d'une succession de faits, Le groupe participial étant plus indiqué dans ces deux cas comme expansion du GN le paracétamol dans la phrase nominale elliptique française est traduit en ukrainien par son correspondant syntaxique, la proposition juxtaposée ukrainienne.

Conclusions et perspectives des recherches ultérieures. En faisant l'analyse des textes des notices de médicament françaises on peut faire le bilan suivant: l'étude de certaines catégories syntaxiques prouve que la notice de médicament française comme genre des textes pharmaceutiques a sa spécificité prédéterminée par les particularités de genre et les objectifs pragmatiques et communicatifs des textes injonctifs et descriptifs. Les notices ont une riche structure syntaxique.

Dans les perspectives des recherches ultérieures on prévoit de révéler les moyens de la reproduction des particularités syntaxiques des textes des instructions techniques pour les appareils électroménagers dans la traduction ukrainienne afin de constater les méthodes et les transformations de traduction. 


\section{References:}

1. Боцман А.В. Структурно-семантичні та прагматичні особливості фармацевтичних текстів(на матеріалі англомовних інструкцій до вживання лікарських препаратів): автореф. дис. на здобуття наук. ступеня канд. філ. наук: спец.10.02.04 «Германські мови»/ Андрій Васильович Боцман. - К., 2006. - 15 с.

2. Буць Ж.В., Ібрагімова С.В. Основи науково-технічного перекладу: навч. Посібник(електронне видання) / Ж.В. Буць, С.В. Ібрагімова. - К.: НТУУ «КПІ», 2015. - 222c.

3. Комисаров В.Н. Теория перевода(лингвистические аспекты) / Вилен Наумович Комисаров. - М. Высшая школа, 1990. - 253с.

4. Латышев Л.К. Технология перевода: уч. Пособие по подготовке переводчиков /Лев Константинович Латышев. - М.: НВИ ТЕЗАУРУС, 2001. - 280c.

5. Носова Л.Н. Особенности структурно-смысловой композиции текстов инструкций к лекарственным препаратам на примере французского языка / Людмила Николаевна Носова. //Филологические науки. Вопросы теории и практики. - 2013.-№1. - С.133-135.

6. Рецкер Я.И. Теория перевода и переводческая практика / Яков Иосифович Рецкер. - М.: Междунар. Отношения, 1974. - 228.

7. Poisson-Quinton S., Mimran R., Mahéo-Le Coadic M. Grammaire expliquée du français/ Sylvie Poisson-Quinton, Reine Mimran, Michèle Mahéo-Le Coadic. - CLE International, 2007. - P.430. ISBN : 978-2-09-033703-7.

\section{Джерела ілюстраційного матеріалу:}

1. Doctissimo : Guide des médicaments [Електронний ресурс] - Режим доступу: http://www.doctissimo.fr/ Guide des médicaments.

2. Пошук ліків в аптеках України [Електронний ресурс] - Режим доступу: https://tabletki.ua/uk/.

3. Extrait du glossaire du Répertoire des Spécialités Pharmaceutiques [Elektronnyi resurs] - Rezhym dostupu : http://agence-prd.ansm. sante.fr/php/ecodex/glossair/glossair.php 